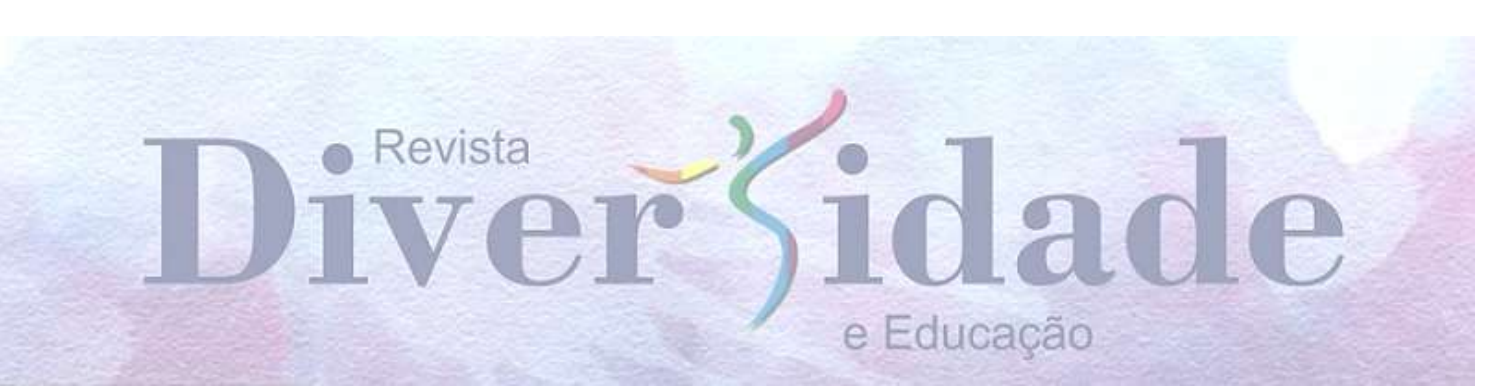

\title{
MULHERES NAS CIÊNCIAS: AÇÕES EDUCATIVAS PARA A REFLEXÃO DO PAPEL DAS MULHERES NO UNIVERSO DAS CIÊNCIAS
}

\author{
MUJERES EN CIENCIAS: ACCIONES EDUCATIVAS PARA REFLEJAR EL \\ PAPEL DE LAS MUJERES EN EL UNIVERSO DE CIENCIAS
}

\section{WOMEN IN SCIENCES: EDUCATIONAL ACTIONS TO REFLECT ON THE ROLE OF WOMEN IN THE UNIVERSE OF SCIENCES}

\author{
Karine Arend ${ }^{1}$ \\ Maria Luiza Machado Silva ${ }^{2}$
}

\section{RESUMO}

As mulheres nem sempre foram representadas nas ciências como deveriam. Muitas contribuições femininas em pesquisas foram negligenciadas na história. Este é um dos fatores da baixa procura das meninas por cursos nas áreas das Ciências, Tecnologia, Engenharia e Matemática. Neste contexto, o projeto "Mulheres que mudarão o mundo" teve como objetivo oferecer um espaço de discussão, resgate, aprendizado e integração para aproximar as meninas do universo das ciências, ampliando seu interesse por essas áreas. Foram realizadas conversas e oficinas com temas de áreas da ciência com alunas do Ensino Médio em duas escolas estaduais e uma federal de São Bento do Sul/SC. A experiência serviu para a reflexão acerca do papel das mulheres no desenvolvimento das ciências e alcançou resultados positivos, motivando as participantes a repensar seu papel no mundo das ciências.

PALAVRAS-CHAVE: Meninas na ciência. Educação. Gênero. Representatividade.

\section{RESUMEN}

Las mujeres no siempre fueron representadas en las ciencias como deberían. Muchas contribuciones femeninas en investigaciones fueron negligenciadas en la historia. Esto es uno de los factores de la baja procura de las chicas por las carreras en las áreas de Ciencias, Tecnología, Ingeniería y Matemática. En este contexto, el proyecto "Mujeres que cambiarán el mundo" tuvo como objetivo ofrecer un espacio de discusión, rescate, aprendizaje e integración para acercar a las chicas al universo de las ciencias ampliando su interés por esas áreas. Fueron realizados talleres y conversaciones con temas de áreas

${ }^{1}$ Graduanda Instituto Federal Catarinense, São Bento do Sul, Santa Catarina, Brasil.

${ }^{2}$ Doutorado Instituto Federal Catarinense, São Bento do Sul, Santa Catarina, Brasil. 
de la ciencia con alumnas de la Enseñanza Media en dos escuelas provinciales y una nacional de São Bento do Sul/SC. La experiencia sirvió para la reflexión acerca del papel de las mujeres en el desarrollo de las ciencias y alcanzó resultados positivos, motivando las participantes a repensar su papel en el mundo de las ciencias.

PALABRAS-ClAVE: Chicas en la ciencia. Educación. Género. Representatividad.

\section{ABSTRACT}

Women have not always been and are represented in the history of science. This is one of the factors in the low demand of girls for courses in the areas of Science, Technology, Engineering and Mathematics. The project "Women who will change the world" aimed to offer a space for discussion, retrieval, learning, integration in order to bring girls closer to the universe of science to awaken, motivate and expand their interest in these areas. These activities were offered to high school students in three schools in the city of São Bento do Sul / SC. The experience was essential for a reflection on the role of women in the development of science and achieved positive results, motivating participants to rethink their role in the world of science.

KEYWORDS: Girls in science. Education. Gender. Representativeness.

$$
* * *
$$

\section{Introdução}

As áreas das Ciências, Tecnologia, Engenharia e Matemática são geralmente ocupadas, tanto no mercado de trabalho como nos cursos técnicos e superiores, por homens. Esta distinção em relação ao gênero nos estudos e no trabalho foi questionada por Cachapuz e colegas (2005), que afirmam que o trabalho científico é dominado por uma minoria e que: "Com claras discriminações de natureza social e sexual: a ciência é apresentada como uma actividade eminentemente "masculina"' (CACHAPUZ et al., 2005, p. 44). Esta "lacuna de gênero" ou "Gender gap" acontece, pois estas áreas têm sido campos acadêmicos e profissionais predominantemente masculinos (UNESCO, 2018).

Aumentar a representação feminina em áreas científicas e tecnológicas é um grande desafio amplamente discutido em espaços escolares a décadas. Em 2001, Soares alertou que a desigualdade de gênero ocorre no Brasil e no mundo, e que a discriminação das mulheres em determinadas áreas é um problema sem fronteiras geográficas, e que, é fundamental ampliar a discussão de igualdade de gênero em campo acadêmico e profissional:

Como mulher e cientista, penso ser fundamental a discussão do problema no Brasil. Muitos, acreditam que o problema não existe, e certamente a mulher brasileira é bem menos discriminada do que as mulheres japonesas! No entanto, as sociedades norte-americanas e europeias são mundialmente reconhecidas por uma política liberal e 
não discriminativa em relação à mulher e mesmo assim constatou-se que a discriminação sexual existe em instituições acadêmicas daqueles países. O Brasil não constitui uma exceção, como muitos poderiam pensar pela ausência de discussão do tópico. (SOARES, 2001, p. 284).

A Declaração sobre a Ciência e o Uso do Conhecimento Científico aprovada na Conferência Mundial sobre Ciência promovida pela UNESCO em 1999, faz referência em relação a desigualdade de acesso à área tecnológica relacionada à questão de gênero:

As meninas e as mulheres de muitos países da região vêm encontrando grandes dificuldades ao tentarem ter acesso ao sistema educacional e, portanto, aos conhecimentos de C\&T. Além do mais, a educação científica vem tomando como base abordagens que excluem as mulheres. Uma participação plena e equitativa das mulheres nas atividades de C\&T irá contribuir para o enriquecimento e a reorientação dos programas, métodos, práticas e aplicações da C\&T (UNESCO, 2003, p. 24).

A história das ciências tem mostrado a participação de muitos homens e de poucas mulheres, não porque elas não tenham participado de inúmeras pesquisas, mas porque os trabalhos feitos por elas não são divulgados na literatura. Tosi (1998, p. 380) descreve que muitas cientistas foram negligenciadas, pois as mulheres que tinham condições de estudar “[...] ficaram relegadas à condição marginal de assistentes ou, no melhor dos casos, de colaboradoras de cientistas conhecidos, ficando frequentemente ignoradas para a posteridade”. Silva e Ribeiro (2014) consideram que: “É preciso problematizar o pressuposto de que a ciência é neutra com relação às questões de gênero, revelando que os valores, e as características socialmente atribuídas às mulheres, são desvalorizados na produção do conhecimento" (SILVA; RIBEIRO, 2014, p. 464).

A ausência dos nomes femininos na ciência é relatada por Chassot (2004), que descreve que a matemática neoplatônica Hipácia (370-415) como sendo a pioneira na história da ciência e, segundo o autor, "estrela solitária" num mundo predominantemente masculino. Chassot (2004, p. 14) afirma que: "Hipácia representa o início de um quase vácuo feminino nas produções da Ciência por cerca de 1.500 anos”. A participação feminina na história da ciência foi finalmente estimulada após a Revolução científica, porém a desigualdade na educação das mulheres parece ter sido um obstáculo para que elas conseguissem alcançar sucesso na área das ciências (TOSI, 1998). 
Historicamente, a invisibilidade das mulheres no mundo das ciências está relacionada com o restrito acesso ao conhecimento científico, que era divulgado em reuniões essencialmente masculinas, e também pelo fato de que suas contribuições geralmente estavam relacionadas ao serviço de auxiliar de pesquisa:

Não obstante suas qualidades e competências, não lhes era permitido $\mathrm{o}$ acesso às intensas e calorosas discussões que aconteciam nas sociedades e academias científicas, que se multiplicaram no século XVII por toda a Europa e tornaram-se as principais instituições de referência da ainda reduzida comunidade científica mundial. No século XVIII, essa situação pouco se modificou e o acesso das mulheres a essa atividade, com poucas exceções, deveu-se principalmente à posição familiar que elas ocupavam: se eram esposas ou filhas de algum homem da ciência, podiam se dedicar aos trabalhos de suporte da ciência: cuidavam das coleções, limpavam vidrarias, ilustravam e/ou traduziam os experimentos e textos. (LETA, 2003, p. 271).

Atualmente, é possível encontrar relatos que mostram que a participação feminina foi muito mais ativa no mundo das ciências, com contribuições importantes nas diferentes áreas. Um deles relata que, Madame du Châtelet, como era conhecida Gabrielle Émilie Le Tonnelier de Breteuil, figura marcante na ciência do século XVIII, foi uma destas mulheres. Ficou conhecida como a amante de Voltaire, mas foi "[...] somente a partir de 1941 que sua influência sobre o pensamento de Voltaire, seu talento matemático e suas contribuições à ciência e à Filosofia começaram a ser objeto de estudo" (TOSI, 1998, p. 388).

$\mathrm{Na}$ área da Química, muito se conhece sobre o trabalho da Madame Curie, porém, outras ainda estão sendo negligenciadas no ambiente escolar, principalmente no Ensino Médio. Palmer (2008) descreve as pesquisas de Elizabeth Fulhame, química escocesa. Seu trabalho foi publicado em livro intitulado Um ensaio sobre combustão, e este indicava que a teoria do flogístico, amplamente aceita pela comunidade científica da época, estava incorreta. Elizabeth estudou, em seu precário laboratório, a química do invisível utilizando soluções de sais de prata sobre lenços de seda para avaliar como a ação do sol pode promover a redução da prata e provocar mudanças de coloração. Seus estudos foram fundamentais nas áreas de cinética e fotoquímica. Porém, considerando que os processos fotográficos desenvolvidos abrangeram a pesquisa de inúmeros cientistas em diferentes áreas, e que estes processos se fundamentam em reações de oxirredução, na área da fotografia seu trabalho não tem destaque, talvez pelo fato de não 
ter tido a sorte de ter boas relações ou porque seu trabalho foi isolado (HACKING, 2019).

Chassot (2004, p. 25) destaca que é preciso “[...] lembrar o que os outros esqueceram e assim construir amarras mais sólidas para viver o presente e projetar um futuro com menos discriminações". Neste sentido, o trabalho de Maia Filho e Silva (2019) descreve o experimento realizado pela física sino-estadunidense Chien Shiung $\mathrm{Wu}$, em colaboração com seu assistente, Irving Shaknov, nas discussões sobre os fundamentos da teoria quântica e que foi fundamental para a Segunda Revolução Quântica. Ainda destacam que, geralmente, a atenção é voltada a personagens tradicionais na área em que Wu atuava. Maia Filho e Silva (2019) destacam que a história das mulheres precisa ser contada para garantir à ciência um status mais justo e representativo. Cabe aos professores utilizar estes resgates das contribuições das mulheres nas ciências para promover uma abordagem junto às estudantes e incentivar o ingresso em áreas tecnológicas, promovendo uma igualdade de acesso.

Esta desigualdade entre homens e mulheres ocorre há séculos e denota uma necessidade de ações no âmbito do ensino que provoquem o rompimento destes padrões preestabelecidos que definem que certas profissões poderiam ou não ser ocupadas por mulheres. Desta forma, muitas mulheres acabam não exercendo a profissão que poderiam e de que gostariam, como afirma Soares (2001, p. 284): “É impossível ignorar que este contingente feminino representa uma força de trabalho qualificada que vem sendo desperdiçada".

$\mathrm{O}$ acesso das meninas ao ensino nas áreas tecnológicas perpassa preconceitos estabelecidos secularmente na sociedade. O estudo de Torres e colegas (2017) mostrou que as meninas participantes de projetos de incentivo para áreas das Ciências Exatas sofrem a influência dos estereótipos de gênero de nossa sociedade. Esta influência pode vir da família, da escola, da comunidade e até mesmo da mídia, o que pode dificultar o interesse por matérias das ciências exatas e por um futuro profissional nessa área (TORRES et al, 2017). Cruz (2007) afirma que, muitas vezes, o(a) cientista é visualizado(a) como sendo um ser superior do sexo masculino, e que esta imagem pode estar contribuindo para uma manutenção da visão predominantemente masculina da ciência, principalmente nas ciências duras.

Este cenário pode ser modificado, e para isto estes obstáculos precisam ser derrubados, pois, segundo Lima (2013, p. 899): "Não é porque os obstáculos se 
fundam na massa cultural que não são derrubáveis”. Desta forma, as dificuldades impostas às mulheres devem ser extintas para que as meninas realizem seus sonhos, como afirmam Schwartz et al:

Se os obstáculos para que as mulheres sigam suas carreiras profissionais forem reduzidos, se a família, os/as professores/as, a sociedade como um todo passarem a incentivar as meninas e as mulheres a ingressar em carreiras científicas, em um futuro próximo é possível que essa situação possa ser revertida e a participação feminina nas carreiras científicas em geral e na informática especificamente aumente significativamente. (SCHWARTZ, et al, 2006, p. 276).

O próprio Plano Nacional de Educação (PNE), em vigor de 2014 a 2024, prevê, em uma de suas metas, medidas que potencializem a participação das mulheres em áreas denominadas de Ciências Exatas (BRASIL, 2014). Entre as medidas possíveis, as instituições podem promover ações para desmistificar este cenário masculino, aproximando as meninas do universo das ciências. Assim, torna-se fundamental rever o papel que as mulheres tiveram nas ciências e divulgar estas pesquisas para que sirvam de inspiração para as meninas, como afirmam Brito, Pavani e Junior (2015, p. 39): "Ampliar o debate sobre a participação de mulheres na ciência significa também pensar numa ciência diferente, inspirada e renovada por experiências de vida historicamente excluídas da produção científica e tecnológica".

Palmer (2008) afirma que a consciência da participação das mulheres na história da ciência é importante para os professores de ciências de amanhã. Assim, é fundamental conhecer o que as mulheres fizeram pela ciência e divulgar para o público feminino com o intuito de se verem representadas, como afirmam Maia Filho e Silva (2019), que reforçam que é preciso resgatar os personagens invisíveis que tiveram sua trajetória negligenciada em detrimento dos ditos grandes cientistas.

Assim, o projeto "Mulheres que mudarão o mundo" teve como objetivo oferecer um espaço de discussão, resgate, aprendizado e integração a fim de aproximar as meninas do universo das ciências para despertar, motivar e ampliar o interesse delas para as áreas das Ciências, Tecnologia, Engenharia e Matemática. As ações educativas realizadas entre alunas de escolas públicas do Ensino Médio envolveram rodas de conversa, oficinas nas diferentes áreas e uma exposição fotográfica com reflexão sobre a vivência realizada durante a aplicação do projeto. 


\section{Metodologia}

As atividades do projeto "Mulheres que mudarão o mundo" foram realizadas para um público inicial de 49 alunas de Ensino Médio de três escolas públicas que se encontram na periferia de São Bento do Sul. Num primeiro momento, as ações educativas foram feitas em escolas estaduais: a Escola de Educação Básica Prefeito Carlos Zipperer Sobrinho, localizada no bairro Centenário, e a Escola de Educação Básica Celso Ramos Filho, localizada no bairro Oxford. Estas escolas foram escolhidas porque recebem alunos e alunas de várias localidades e de condições distintas de renda, sendo a maior parte de famílias de classe média-baixa. Num segundo momento, as atividades do projeto foram desenvolvidas no Instituto Federal Catarinense - campus São Bento do Sul, localizado no bairro Centenário, pois é uma instituição de ensino com cursos na área tecnológica. Nesta segunda etapa, a avaliação das atividades foi feita através de duas fichas: uma inicial, abordando as expectativas em relação à proposta projeto, aplicada durante o período de inscrição, e outra avaliativa de todas as ações educativas, aplicada no final das atividades. Os dados coletados nas fichas foram utilizados para discussão final com a equipe do projeto. Nas fichas, que as alunas preencheram de forma anônima, as participantes receberam numeração para avaliação das informação coletadas.

Este projeto envolve várias atividades nas escolas participantes: rodas de conversa, oficinas, uma exposição fotográfica e o encerramento para reflexão sobre as ações educativas realizadas. Essas atividades ocorreram no período entre março a novembro de 2019.

As rodas de conversas foram realizadas no primeiro e no último momentos para abordar a importância de mulheres nas ciências através de um resgate histórico de muitas pesquisadoras, também, para instigar abordagens em relação a seu papel no mundo atual, para que as meninas possam se sentir capazes.

As oficinas de Química abordaram a aplicação desta ciência na fotografia. A reflexão sobre as ciências na fotografia foi instigante para que as alunas tivessem a compreensão de como ocorreu a evolução dessa arte. Além de mostrar o trabalho de duas cientistas, Elizabeth Fulhame e Anna Atkins, houve a realização de atividades práticas envolvendo a escrita invisível e a cianotipia (AREND et al, 2019). 
As atividades de Física consistiram em dois momentos, primeiro foi na reflexão sobre o papel da mulher na ciência e qual a realidade que as alunas percebem no ambiente de ensino em que estão inseridas. A segunda parte, consistiu na confecção de um foguete impulsionado por pressão. Inicialmente, para introduzir as meninas nos assuntos envolvidos, abordaram-se conceitos físicos sobre a trajetória de um objeto, resistência do ar, pressão, etc. Para planejar a elaboração do foguete, as meninas foram divididas em grupos na sala de aula e produziram conforme as instruções fornecidas. Em seguida, as meninas tiveram tempo para testar a quantidade de vinagre e bicarbonato de sódio ideal para propulsionar o foguete, medindo a distância que foi atingida. Após a atividade prática, foram discutidas quais técnicas e mudanças foram adotadas para obter melhores resultados.

A outra oficina foi feita abordando duas temáticas: a eletrostática e a elétrica. Inicialmente, explicou-se o significado de eletrostática com exemplos do cotidiano e ressaltaram-se as situações de risco que envolvem o trabalho com a fiação elétrica. Em seguida, foi realizada uma competição entre as alunas utilizando uma lata de alumínio, cano de PVC, pedaços de papel e papel picado. Na competição, duas alunas deveriam ionizar o cano de PVC com o papel, e ganhava quem atraía a latinha para o seu lado. Para exemplificar isto, o professor ionizou o cano e demostrou que os papéis picados eram atraídos pelo PVC, e o mesmo acontecia com a lata. A parte da elétrica foi abordada em outro encontro com uma discussão sobre os conceitos relacionados, tais como: tipos de fiação elétrica, como fazer emendas da fiação, técnicas de corte, etc. Após as instruções, elas montaram um circuito com uma lâmpada e um interruptor.

A oficina de programação foi feita, num primeiro momento, com a implantação de uma sequência didática através de um jogo colaborativo, por meio do qual puderam vivenciar e compreender a ideia de uma linguagem de programação. O segundo momento, foi feito com a execução de uma atividade no laboratório de informática, por meio de uma pseudolinguagem de programação (SILVA; WITT; MARINI, 2019).

Após o término de todas as oficinas, foi realizado um encontro final no IFC com as pessoas envolvidas no projeto. Neste momento, foi destacada a exposição das fotos das diferentes atividades envolvidas, mas principalmente, a discussão dos dados coletados nas fichas de avaliação que as alunas preencheram de forma anônima. Também, foi o momento de discutir sobre as ações do projeto e perceber o quanto foi importante proporcionar para as alunas um espaço de discussões sobre a igualdade de 
gênero no ensino e, o quanto situações inadequadas podem impactar na escolha de suas profissões.

\section{Resultados e Discussão}

A avaliação inicial, com os dados coletados nas fichas de avaliação, mostrou que as expectativas em relação ao projeto indicaram que muitas gostariam de aprimorar e adquirir mais conhecimento para além do abordado em sala de aula. A aluna 1 observou que seria interessante conhecer as áreas onde não é tão comum a presença da mulher: “Conhecer diferentes áreas nas quais uma mulher pode trabalhar mesmo não sendo tão comum", o que reforça o nosso objetivo. Outra, aluna 2, tem perspectivas de futuro: "Ampliar meus conhecimentos relacionados com o espaço ocupado por mulheres, como elas chegaram até onde estão hoje e como será no futuro". Já a aluna 3 indica que o projeto pode provocar mudanças de perspectivas em relação à sua trajetória profissional: "Eu vejo como uma oportunidade de descobrir outras coisas além do que já conheço e que podem ser úteis um dia, além de descobrir um novo mundo com outras perspectivas".

Em relação ao futuro que imaginam ter, há relatos indicando que atualmente percebem os obstáculos em relação ao gênero, como a aluna 4: "Pretendo fazer Engenharia Mecânica e não ser subestimada na área por ser mulher"; e a aluna 5: "No futuro, eu me vejo me formando na faculdade e exercendo algo na informática, onde eu possa mostrar que a informática também é um espaço para as mulheres terem opinião e visibilidade, além de ajudar a quebrar o famoso estereótipo de que informática é coisa para homem". Já a aluna 6 deixa claro que a igualdade deve estar presente no ambiente de trabalho: "Quero ter direitos iguais aos homens, poder escolher qualquer área sem sofrer preconceito, receber o mesmo salário e exercer cargos tão importantes quanto os que qualquer homem possa exercer".

As falas das alunas participantes, após o final das ações educativas, demonstram que as rodas de conversas propostas foram de fundamental importância para um momento de reflexão feminino. Também o fato de os encontros terem sido feitos somente com mulheres proporcionou liberdade para se expressarem sobre as questões debatidas.

Aluna 7: Fundamental para entendermos por que o projeto é necessário, com as conversas também fomos capazes de nos colocarmos no lugar umas das outras, 
ter diferentes pontos de vista. Observei também que, mesmo tendo só mulheres ali, ainda tinha um preconceito, o qual fomos ensinadas a ter desde pequenas, refleti muito sobre a dinâmica de tentarmos adivinhar a profissão das mulheres e vi que ainda temos muito a mudar dentro de nós.

Aluna 8: Por estarmos apenas entre mulheres ali, conseguimos ter mais liberdade em falar e aprender coisas que não são "comuns" para as mulheres, foi algo que abriu nossas mentes para coisas novas também.

Em relação à participação das mulheres nas áreas das Ciências, a fala da Aluna $\mathrm{C}$ indicou que a percepção do que as mulheres fizeram, através das suas pesquisas, parece ser imprescindível para a motivação, pois assim percebem que a Ciência não é e nunca foi um espaço masculino. Ela destaca que é uma luta das mulheres para entrar nos ambientes científicos. Chassot (2004, p. 22) afirma que estas mudanças não são rápidas, pois “[...] não se desconstrói, no espaço de duas ou três gerações, preconceitos milenares". Carvalho e Casagrande (2011, p. 33) ressaltam que: "A participação das mulheres na ciência foi um processo longo de muitos desafios e lutas, mas também de muitas conquistas", e é devido ao mérito das pioneiras que muitas conseguiram chegar onde chegaram.

Aluna 9: A experiência de participar do projeto, não apenas para mim, mas, com base nas rodas de conversas, foi uma das melhores que poderiam ser esperadas. Pudemos perceber diversas contribuições das mulheres em diversas áreas onde, muitas vezes, nem sabíamos citar os nomes delas e seus estudos, percebemos que, apesar de esta situação estar mudando, ainda é uma luta que nós, mulheres, passamos para entrarmos em ambientes científicos, devido à exclusão que sofremos por sermos mulheres. O projeto pode abrir nossos olhos para o fato de que lugar de mulher é onde ela quiser.

A abordagem de diferentes conteúdos fez com que muitas tivessem o contato pela primeira vez com determinado assunto. Nas avaliações feitas por muitas, percebese que o interesse delas nestas áreas existe, ainda que, muitas vezes o conhecimento é novo. Assim, este conhecimento torna-se essencial para que possam adquirir sua independência, como mostra a fala da aluna 12. 
Aluna 10: Programação: foi legal ter contato com uma matéria de outro curso. Gostei muito e sei que, se não fosse pelo projeto, eu provavelmente não teria experienciado isso.

Aluna 11: Eletrônica: com toda certeza, foi muito interessante e divertido instalar uma lâmpada e fazê-la acender.

Aluna 12: Eu achei e ainda acho um projeto incrível, pois é possível que aprendamos coisas que não vemos no dia a dia, mas que sempre precisamos, e o fato de sabermos fazer nos livra de depender de alguém.

Aluna 13: Muito interessante, gosto bastante de fotografia, e aprender um pouco sobre a relação com a química foi muito legal.

A motivação das alunas instigada pelos(as) professores(as) foi destaque em algumas falas. Esta motivação também é percebida em outros projetos, como o desenvolvido pela equipe de Torres (2017, p. 154), que demostrou a necessidade de que "[...] essas ações possam fortalecer a imagem de que as áreas das Ciências, Tecnologia, Engenharia e Matemática devam também ser atuadas pelas mulheres”. Estas atividades podem promover a percepção das suas capacidades, a compreensão de que elas podem fazer o que querem, sem preconceitos culturais preestabelecidos.

Aluna 14: A professora me encorajou a acreditar que eu consigo fazer qualquer coisa se eu quiser, e esse foi o maior ensinamento que aprendi.

Aluna 15: O projeto foi uma experiência muito bacana. É muito legal ver nós, meninas, procurando nos engajarmos em áreas que são consideradas "para homens", e acho que mais projetos como esse deveriam surgir para encorajar mais meninas a fazerem o que gostam.

Aluna 10: É muito bom saber que existem pessoas que acreditam na força feminina, e que fazem questão de mostrar a todas que podemos ser o que quisermos e o quão capazes somos disso.

Os resultados indicam que a proposta realizada alcançou os objetivos de oferecer um espaço de discussão, resgate, aprendizado e integração a fim de aproximar as meninas do universo das ciências. A Figura 1 mostra uma aluna manipulando materiais elétricos, explorando com facilidade estas novidades no seu cotidiano. 
FIGURA 1: Oficina de Eletrônica EEB Celso Ramos.

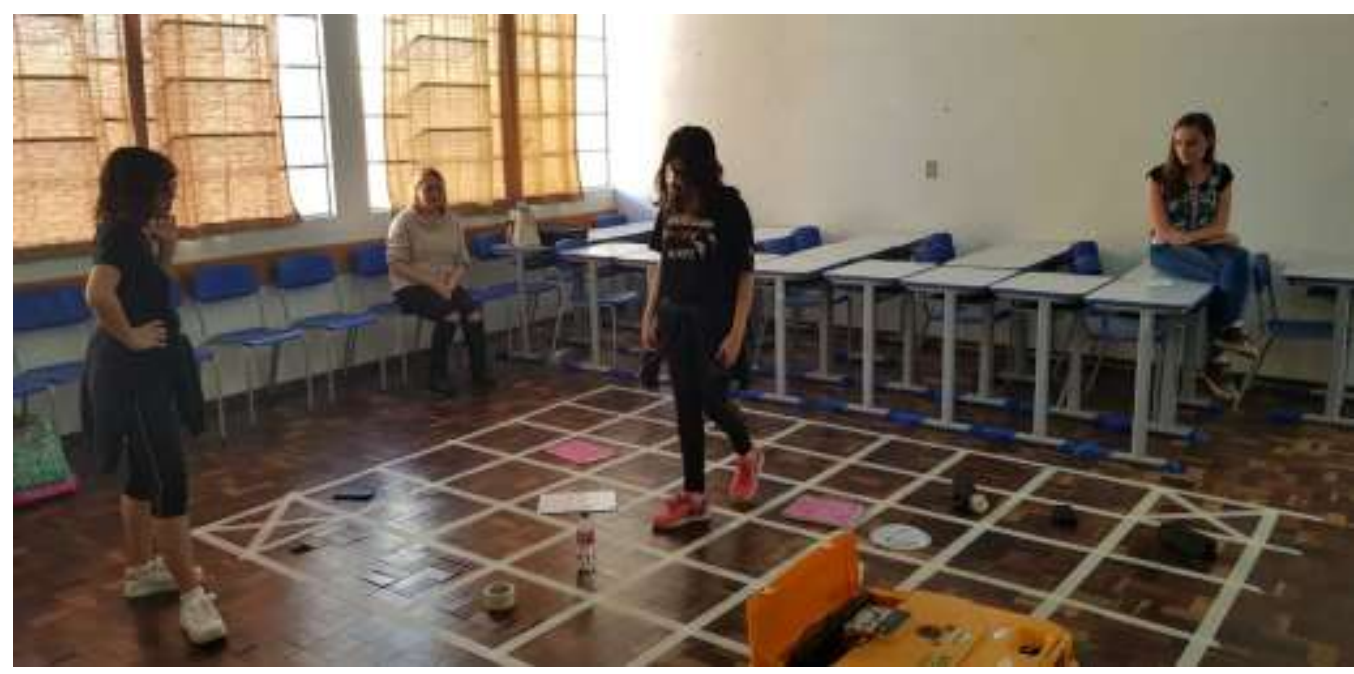

Fonte: As autoras

A sensação de empoderamento delas está implícita nos depoimentos da avaliação do projeto.

Aluna 12: Eu gostei muito! Aprendi coisas de que não tinha conhecimento nenhum, e me mostrou que as mulheres merecem um lugar no mundo!

Aluna 14: Foram dias incríveis, nos quais eu aprendi muito, mesmo em áreas com as quais nunca havia tido contato. É um projeto incrível e que deve ser continuado.

Aluna 16: Nas rodas de conversas, o objetivo que eu identifiquei foi o de você repensar o seu futuro, o seu presente e o seu passado e, principalmente, pensar que você tem o poder em suas mãos, é só saber manipular.

No contexto apresentado, é perceptível a importância de um momento exclusivo de atividades para as alunas. O projeto "Mulheres que mudarão o mundo" conseguiu oferecer um espaço para repensar o papel da mulher na ciência e como devemos e podemos mudar a história da ciência. Não só através do resgate da história das mulheres nas ciências, mas promovendo uma "[...] consciência crítica de gênero na formação básica de jovens cientistas e no mundo rotineiro da ciência”, como sugere Schiebinger (2001, p. 31).

A experiência desta proposta proporciona uma vivência única que nem sempre pode ser descrita. Brito, Pavani e Junior (2015, p. 45), que também desenvolvem ações educativas com as meninas, descrevem: "Esses aprendizados, por mais ricos, geralmente não ficam registrados em documentos oficiais, mas na experiência prática dos 
participantes”. Ressaltam, ainda, que o apoio institucional é fundamental e que é preciso debater estas questões com o corpo docente visando à permanência das alunas em cursos.

Atividades de promoção das mulheres às áreas das ciências exatas, como a realizada por este projeto, devem ser contínuas, visto que as participantes percebem que possuem obstáculos referentes ao fato de serem mulheres e que isso está implícito na sociedade como se fosse algo comum. Lima (2013, p. 899) afirma que o caminho para elas é mais tortuoso e que a superação destes obstáculos é perfeitamente viável: "A promoção da igualdade de gênero nas ciências viabilizará a participação ampla das mulheres, que poderão melhor contribuir para a ciência e tecnologia e serem reconhecidas por suas contribuições”. Considerando o exposto acima, devemos continuar a realizar ações educativas para evitar que uma força de trabalho qualificada continue sendo desperdiçada.

\section{Conclusão}

O projeto foi fundamental para que pudéssemos provocar a reflexão de que todas meninas participantes podem ir e chegar aonde querem, mesmo que ainda haja uma resistência muito grande à participação feminina em certas áreas tecnológicas. As atividades de cunho tecnológico, abordando as importantes contribuições femininas nas áreas das Ciências e Tecnologia, foram motivadoras para as meninas participantes, fazendo com que percebessem suas capacidades na escolha da profissão sem preconceito de gênero.

As abordagens realizadas nas ações didáticas puderam fortalecer a imagem de que as áreas das Ciências, Tecnologia, Engenharia e Matemática devem ser mais frequentadas pelas mulheres. Assim, considera-se que é preciso continuar instigando as meninas ao universo das ciências para despertar, motivar e ampliar o interesse delas para estas áreas modificando o mundo das ciências com suas contribuições.

\section{Referências}

AREND, Karine; PACHECO, Nalanda C.; STASCHECK, Alana.; SILVA, Maria Luiza Machado As mulheres que mudarão o mundo: o exemplo feminino na química da fotografia. In: $17^{\circ}$ SIMPEQUI (Simpósio Brasileiro de Educação Química), 2019, 05 - 07 de agosto. Porto Alegre/RS: Sociedade Brasileira de Química, 2019. 
Disponível em: http://www.abq.org.br/simpequi/2019/trabalhos/90/496-20540.html. Acesso em: 05 mai. 2020.

BRASIL. Plano Nacional de Educação - PNE/Ministério da Educação. Brasília, DF: INEP, 2014.

BRITO, Carolina; PAVANI, Daniela; JUNIOR, Paulo Lima. Meninas na ciência: atraindo jovens mulheres para carreiras de ciência e tecnologia. Revista Gênero, Niterói, v. 16, n. 1, p. 33-50, 2015.

CACHAPUZ, Antônio.; GIL-PEREZ, Daniel.; PESSOA DE CARVALHO, Ana Maria; PRAIA, João; VILCHES, Amparo. Superação das visões deformadas da ciência e da tecnologia: um requisito essencial para a renovação da educação científica. In: A necessária renovação do ensino das ciências. São Paulo: Cortez, 2005. Cap. 2, p. 37-70.

CARVALHO, Marília Gomes de; CASAGRANDE, Lindamir Salete. Mulheres e ciências: desafios e conquistas. Interthesis. Florianópolis, v. 8, n. 2, p. 20-35, jul./dez. 2011. Disponível em:

https://periodicos.ufsc.br/index.php/interthesis/article/view/18071384.2011v8n2p20/20565. Acesso em: 05 mai. 2020.

CHASSOT, Áticco. A ciência é masculina? É, sim senhora!... Contexto e Educação Editora Unijuí: Ijuí - Ano 19 - n 71/72 - Jan/dez 2004 - p. 9-28 Disponível em: http://www.saci.ufscar.br/data/solicitacao/39867_texto_a_ciencia_e_masculina.pdf Acesso em: 05 mai. 2020.

CRUZ, Joliane Olschowsky. Mulher na ciência: representação ou ficção. 2007. 242 f. Tese (Doutorado em Ciências da Comunicação). Escola Comunicações e Artes, Universidade de São Paulo, São Paulo, 2007.

HACKING, Juliet. Tudo sobre a fotografia. Rio de Janeiro: Editora Sextante, 2019, $576 \mathrm{p}$.

LETA, Jaqueline. As mulheres na ciência brasileira: crescimento, contrastes e um perfil de sucesso. Estudos Avançados. São Paulo, v. 17, n. 49, p. 271-284, dez. 2003.

LIMA, Betina Stefanello. O labirinto de cristal: as trajetórias das cientistas na física. Revista de Estudos Feministas, Florianópolis, v. 21, n. 3, p. 883-903 set./dez. 2013.

MAIA FILHO, Angevaldo Menezes; SILVA, Indianara. O experimento WS de 1950 e as suas implicações para a segunda revolução da mecânica quântica. Rev. Bras. Ensino Fís., São Paulo, v. 41, n. 2, 2019. Disponível em:

http://www.scielo.br/scielo.php?script=sci_arttext\&pid=S1806-

11172019000200704\&lng=pt\&nrm=iso. Acesso em: 6 abr. 2020.

PALMER, Bill. Elizabeth Fulhame: The Invisible Chemist. Teaching Science, v. 54 n. 4 p. 12-16, dec, 2008. 
SCHWARTZ, Juliana; CASAGRANDE, Lindamir Salete; LESZCZYNSKI, Sonia Ana Charchut; CARVALHO, Marilia Gomes de. Mulheres na informática: quais foram as pioneiras? Cad. Pagu, Campinas, n. 27, p. 255-278, dez. 2006. Disponível em: http://www.scielo.br/scielo.php?script=sci arttext\&pid=S0104-

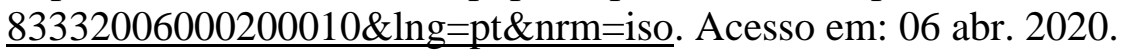

SCHIEBINGER, Londa. O feminismo mudou a ciência? São Paulo: EDUSC, 2001. $375 \mathrm{p}$.

SILVA, Fabiane Ferreira da; RIBEIRO, Paula Regina Costa. Trajetórias de mulheres na ciência: "ser cientista" e "ser mulher". Ciênc. educ. (Bauru), Bauru, v. 20, n. 2, p. 449-466, 2014. Disponível em:

http://www.scielo.br/scielo.php?script=sci_arttext\&pid=S151673132014000200449\&lng=en\&nrm=iso. Acesso em: 05 mai. 2020.

SILVA, Maria Luiza Machado; WITT, Diego; MARINI, Andréia. Ensino de algoritmos e lógica de programação para meninas no Ensino Básico. In: VIII Congresso Brasileiro de Informática na Educação (CBIE 2019), 2019. Brasília/DF. Anais do VIII Congresso Brasileiro de Informática na Educação. Disponível em: https://www.researchgate.net/publication/337383586_Ensino_de_Algoritmos_e_Logic a_de_Programacao_para_Meninas_no_Ensino_Basico Acesso em: 05 mai. 2020.

SOARES, Thereza Amélia. Mulheres em ciência e tecnologia: ascensão limitada. Quím. Nova, São Paulo, v. 24, n. 2, p. 281-285, apr. 2001. Disponível em: http://www.scielo.br/scielo.php?script=sci arttext\&pid=S010040422001000200020\&lng=en\&nrm=iso. Acesso em: 05 mai. 2020.

TORRES, Kely Beatriz Vieira; BERNARDES, Rayane Monique; QUEIROS, Priscila Soares de; VIEIRA, Taynara Mara; FELIX, Josemar Coelho; DE URZEDO, Ana Paula Fonseca Maia; SOUZA, Deborha Hinácia Loyola; MENDES, Tuane Tayrine. Inclusão das mulheres nas ciências e tecnologia: ações voltadas para a educação básica Expressa Extensão, v. 22, n. 2, p. 140-156, jul-dez, 2017. Disponível em: https://periodicos.ufpel.edu.br/ojs2/index.php/expressaextensao/article/view/11847. Acesso em: 11 mai. 2020.

TOSI, Lucia. Mulher e Ciência a Revolução Científica, a Caça às Bruxas e a Ciência Moderna* Cadernos Pagu, v. 10, p. 369-397, 1998. Disponível em: https://periodicos.sbu.unicamp.br/ojs/index.php/cadpagu/article/view/4786705. Acesso em: 11 mai. 2020.

UNESCO. A ciência para o século XXI: uma nova visão e uma base de ação-Brasília: UNESCO, ABIPTI, 2003. 72p.

UNESCO. Decifrar o código: educação de meninas e mulheres em ciências, tecnologia, engenharia e matemática (STEM). Brasília, Unesco Brasil, 2018. Disponível: https:// unesdoc.unesco.org/ark:/48223/pf000026469. Acesso em: 27 nov. 2020. 